\title{
Life Scenery of Javanese Person With Type 2 Diabetes
}

\author{
$1^{\text {st }}$ C. Septiwi \\ STIKES Muhammadiyah Gombong \\ Jalan yos Sudarso 461 Gombong, Kebumen, \\ Jawa Tengah, Indonesia \\ cahyuseptiwi@stikesmuhgombong.ac.id
}

\author{
$2^{\text {nd }}$ S. Rungreangkulkij \\ Faculty of Nursing \\ Khon Kaen University \\ Thailand
}

\begin{abstract}
Cultural beliefs and tradition influence of the Javanese persons perception related to diabetes and how they manage diabetes in their daily lives. Ethnography was used in this study to understand the cultural management of Javanese person living with type 2 diabetes. The data were collected by focus group discussion, in-depth interview, and participant observation from 34 Javanese people with diabetes and their family. Through thematic analysis, the result showed 3 themes that illustrated the cultural diabetes management of Javanese person in daily lives. The themes are: (1) Living with the peaceful mind and following the diabetes guideline (2) Living with worry after passing worst experience (3) Living with following the guideline but occasional offence it. Javanese culture plays an important role in diabetes management among Javanese person. Understanding about Javanese culture is useful for designing a model of diabetes care which is appropriate with Javanese culture in order to achieve the effectiveness of diabetes management among Javanese person.
\end{abstract}

Keywords-Cultural management, Javanese person living with type 2 diabetes, ethnography

\section{INTRODUCTION}

Diabetes is one of the most common metabolic disorders and important causes of death and disability in the world. Based on data from the International Diabetes Federation, 400 millions of people in the world have diabetes and by 2035 it will be increasing to 592 million [1]. Indonesia, a developing South-East Asian country, is the top four countries with a higher number of diabetes people, and by 2030 will be increased to 11.8 million [2]. The data from RISKESDAS at 2013 (National Basic Health Research) in Indonesia shows that type 2 diabetes prevalence increased and very high in Java Island [3].

Type 2 diabetes is a disease that combines from a biological and cultural problem such as foods and lifestyle practices. Anthropologist Edmund Tylor (1871) defined culture as the complex whole which includes knowledge, belief, art, morals, law, custom, and any other capabilities acquired by man as a member of society. Culture also defined as shared ideas, meanings, values, and patterns of behaviour that learned socially (not genetically and often exists at an unconscious level), and constantly being modified through life experiences [4].
Related to health and illness, cultural beliefs and traditions influence their perceptions and their way to perceive the causes, react to symptoms, choose to treatments, and compliance of health professional's instruction. Individuals' perceptions of health and illness and the ability to modify unhealthy lifestyle behaviours are influenced significantly by socio, cultural and psychological factors responding toward illness [5]. A lack of understanding of diabetes makes them difficult to adapt to the situation and to raise low awareness among persons and increase the risk of psychological problems [6].

Diabetes is a lifelong condition has impacts on the persons aspects of life. Living with diabetes treated persons to readjust their role and accept the disease that important thing to successful diabetes management. Diabetes development and treatment are influenced by culture, such as food habits including the ways of production, consumption, and serving the diet in their daily life. Having diabetes makes changes to previous routines and often to provoke stress, anxiety, and fear, also impact to personal and interpersonal relationships. The success of diabetes management requires that patients can perform good management in daily life [7]. Understanding beliefs about diabetes in each culture is important to know how people understand and manage their illness and essential for creating and implementing culturally-appropriate diabetes care. Experiences have shown that health programs are unsuccessful and not working, because they fail to recognize and deep-understanding about the cultural beliefs and behaviours practices [4].

Based on RISKESDAS data (2013), the prevalence of diabetes is very high in Java Island. The increasing rate of type 2 diabetes among Javanese people needs deep exploration of their culture related to diabetes, in order to find the needs of Javanese diabetes patients and how they manage their illness, and In order to understand about the Javanese culture related to diabetes. Learning from the people is one way to understand phenomena relevant to health needs of the multi-ethnic population, and exploring health and illness beliefs, linkages beliefs and actions and health-seeking behaviour among diabetes persons. Their beliefs, ideas, and values about diabetes influence their 
health practices and provide information for designing effective diabetes care that is appropriate for their culture. It is important to organize illness and health within sociocultural contexts, to explain how people view their illness in term of how it happens, what causes it, how it affects them, and what will make them feel better. This way could explore the meaning of health and illness and linkage with behaviour, enhancing understanding of how cultural norms and life experiences contribute to such beliefs and actions related to diabetes. It is important to organize illness and health within socio-cultural contexts, to explain how people view their illness and its management [8]. Thus, the aim of this research is to understand the cultural management of Javanese person living with type 2 diabetes.

\section{MATERIALS AND METHODS}

\section{A. Study design and Setting}

Ethnography is essential to understand health phenomena within cross-cultural settings because it enables researchers to observe, examine, and assemble multiple images of illness and health to understand and to interpret an individual's perception and behaviour toward diabetes. Ethnography was used in this study to understand the Javanese culture, the beliefs, and behaviours, in order to find an in-depth perspective in the real situation of cultural management in their daily lives. The study was conducted in a sub-district of Central Java Province, Indonesia.

\section{B. Research Instrument}

The main instrument in this research was researcher herself, who prepared by learning the qualitative research concepts and theories, attended the workshop of qualitative research, and trained in the field study with the advisor in the research practicum. The researcher used a form of guideline for focus group discussion, in-depth interviews, and observation. The interviews were based on the following questions: 1) What is in your mind when you hear diabetes? Why?; 2) Could you tell me how you know about diabetes? When? Who tell you about diabetes?; 3) What do you feel when you diagnosed with diabetes? What are you doing after having got diabetes? Please tell me about your experience related to diabetes.; 4) Could you tell me about the impacts of diabetes in your life? How do you solve this condition? Who help you in this situation?. The guideline was made by the researcher that was based on kinds of literature, consulted, and revised by a discussion with an advisor. The researcher also used recorder device during conducted the interview with key informants and used field notes as well.

\section{Key Informant}

The total key informants in this study were 34 persons, including 17 persons who live with type 2 diabetes, and 17 persons of the family member who takes care of the persons. The access to the key informants was administered through the gatekeeper information, and purposive sampling was used for selecting potential key informants who met the study eligibility criteria as follow: 1) person who is diagnosed type 2 diabetes at least 1 year (for person) and take care the person with diabetes at least 1 year (for the family member), both male and female, age 18 years old and over, self-identified as Javanese, who is able to communicate in Javanese or Indonesian language, and person who has willingness to participate in this study.

\section{Ethical Considerations}

The research was approved by the Institutional Review Board of the Khon Kaen University Ethics Committee for Human Research. After the researcher receives approvals from the ethical committee of Khon Kaen University, information about the study will be distributed to the study site. The information about the study objective and procedure will be provided to the potential informants. If they are still interested in participating, they need to sign a consent form. They have the right to reject to participate in this study and can retire anytime without any effect on their care and treatment. All information obtained from each informant is treated confidently. Their identities will remain anonymous and, instead, will be identified with a numerical code, and the results of the study will be presented as a whole, not specific to each individual.

\section{E. Data Collection and Data Analysis}

After the research was approved by the Institutional Review Board of the Khon Kaen University Ethics Committee for Human Research, the researchers undertook data collection from January to August 2018. The researcher met the gatekeeper who known the study site situation and involved in a diabetes management program in the community. Researcher entered the area accompanied by the gatekeeper to introduce the researcher to the persons and their family, to build trust and relationship, observe the situation at the study site, and observe their daily activities related to diabetes management. In this study, the researcher used a variety of data collection methods, including 1) Focus group discussion with diabetes persons for 90 minutes to sharing ideas, beliefs, and perceptions about diabetes and its management, 2) In-depth interviews with 17 persons with diabetes and 17 family member and lasting 60 minutes each, and 3) Participant observation of daily activities related to diabetes management in their daily life. After having finished the collection, the data were sorted and used thematic analysis in order to formulate the identification and development of themes. A theme was grouping ideas or meanings from the data. Matrix and typology were necessary and make easier to name, formulate, and develop the themes and sub-themes.

\section{F. Trustworthiness}

Trustworthiness was reflected in four criteria: credibility, dependability, transferability, and confirmability [9], [10]. In this study, credibility was addressed by member checking and debriefing with the advisor. Dependability related to solidity the findings of study over time and can reply in other setting or other setting or population. To establish the dependability of this study, the researchers used several methods and several times and events to collect data, and data were checked and confirmed. Transferability related to the possibility of the findings that can be applied outside the context of the study situation or not. The researcher reviewed every audiotape and transcription to ensure that verbal and conceptual translations that were aligned and able to determine the 
applicability of study findings to other study groups or settings. Confirmability established by triangulation, which involves having multiple points of view when gathering data, was addressed by having multiple data sources. Another information source such as field note and data of observation in the triangulation process was the creation of transcripts for each transcript.

\section{RESULTS AND DISCUSSION}

Based on finding in this study, the researcher identified there were three living scenes the Javanese people living with diabetes in Javanese culture as follow:

\section{A. Faith in God and living with peaceful}

As a Muslim, Javanese people believe that everything occurring in the world is destiny from God, involved diabetes. They also believe that God gives them sickness as a trial to remission their sins if they can be patient through it. Islam teaches people to surrender to God when they sick and must try to find the healing by treatment of the disease. According to them, surrendering to God is one of the important things that always encourage them to accept diabetes as part of their lives. Belief and faith in God also make them able to accept their destiny with peaceful and enhance their ability to adapt and compromise with their illness. Peace is a feeling of secure, immunity from lifes problems, love, and affection from surrounding people. Those perspectives mentioned by persons and family members as below:

In the beginning, It is not easy to accept that I must spend my life with diabetes, but as Muslim I really believe that everything occurs by God willing and I must accepted as part of my life. When I give back everything to God, I do not consider that my endeavor to manage my diet, walked out in the every morning, and take the medication every day as a burden...just enjoy my life. (IDO3PF, 65 y.o) I always to remind to my wife that Islam teaches us to surrender to God, Islam also teach us not just surrender but need to endeavor to follow every advices from health care provider. (IDI2SM, 47 y.o)

According to them, a peaceful mind gives them the power to follow diabetes guideline in order to manage their disease. They follow the health care providers advice, follow the diabetes guideline to plan the meal, take medication properly, doing a simple physical activity such as walking in every morning, ride the bicycle, and gymnastics, and also enthusiastic join to diabetes program at PHC every month. They realize that living with diabetes need the discipline to manage themselves in daily living. Belief and faith in God give people the ability to accept their destiny with peaceful and enhance their ability to adapt and compromise with their illness.

The importance of addressing spirituality in diabetes management is indicated in several studies. Previous studies showed that there is a positive relationship between spiritual well-being and coping with diabetes, glycemic control, and self-management. There is a strong association between spirituality and coping with a chronic medical disease [11], willingness to live [12], reducing anxiety and depression [13], and improving quality of life [14]. This finding also supported by study of [15] stated that spirituality/religion is the aspect of humanity that refers to the way individuals seek and express meaning and purpose and the way they experience their connectedness to the moment, to self, to others, to nature, and to the significant or sacred. Similarly, the study of [16] shown peace of feeling as an important resource for cancer survivors, and faith serves to facilitate positive adjustment to their illness. A previous study of [17] on diabetic patients indicated that higher spiritual well-being is associated with lower HbA1c and better adjustment to disease. The findings of this study reflect that the sense of inner peace and intrinsic strength may guard against negative feelings and probably result in maintaining higher self-care behaviours and thus, greater glycemic control in those with diabetes. This highlights the need for considering spiritual issues in caring for diabetic patients.

B. Following the diabetes guideline after having passed the worst experiences

Worrying about the present and the future is a real issue for persons with type 2 diabetes. As a chronic disease, persons who live with diabetes need a long term adjustment in their lives. Living with long medication, lifestyle modification, diabetes complication, and fear experiences such as hypoglycemia or hyperglycemia and a threat of amputation may lead to worry or anxiety. People in this group through their living with diabetes with worry because they have the worst experiences of diabetes as follow. In the beginning, they think that diabetes is not a serious problem. They believe that God gives them diabetes as their destiny and must receive it as a part of their life. They take medication regularly but sometimes not follow the dietary guideline. This behaviour makes them have the worst conditions. One of them has high blood sugar level, had a bad wound in her leg, and faced threatening of amputation. Her wound has bad progress, more wide day by day, bad smell, and the physician advises to amputate her leg to prevent the wound expanded. She rejected that advice and choose the nurse to take care of her wound. Even though it needs takes a long time, her wound can be healed and she spared from a leg amputation. This scary experience makes her worry if she gets the wound again, therefore she follows the guideline to avoid it.

... after got the wound, I living in worry and fear condition. Have high blood sugar and bad wound in my leg are very scary experiences in my life. This disease almost makes me lose my leg because of amputation.....Now my wound healed and this is a miracle that I can walk again. Sure I am worried if my blood sugar is high and have wound again. (IDO8PF, 63 y.o)

... I feel worried if this disease can make me die if my blood sugar increased, so I am very strict with my diet, just eat a little bit of rice and never drink with sugar. Two times I feel that I almost die, because I feel very weakness and dizziness, almost unconsciousness, cannot call out my daughter, cannot move, just lying on the floor, it is very bad. Alhamdulillah, my daughter bring me to the 
hospital quickly, God still gives me a long live.....but honestly I am worried if it happens again.(IDO3PF, 65 y.o).

Family always support persons with diabetes and help them to discipline and follow the guideline in order to avoid those bad experiences. That condition makes them scary and worry through their life with diabetes and worry if face it again. They strictly follow the dietary guideline from HCPs, always provide food by themselves and avoid to eat outside to prevent their blood sugar level increase. They always take the medication properly after a meal because they believe that medication is very important to keep their blood sugar level stable. They also consult HCPs about their condition and make sure that they are in good condition. They also worry and believe that diabetes is a dangerous disease that has many complications that they heard from HCPs and neighbours, such as amputation, blindness, and death. They are able to keep their blood sugar level in stable condition, but they still worry through their daily lives.

The previous study by [18] identified that women with diabetes reported having worry and anxiety. Feelings of stress, worry, depression, and anxiety in persons with diabetes have been reported. Stress and worry can occur when blood sugar levels drop too low, it makes people can become disoriented and may pass out. Blood sugar levels that are too high and left untreated over time can cause complications such as kidney troubles, eye problems, and heart disease. Another important finding is that struggling with a changing health situation causes restrictions in dayto-day living. Concerns about controlling blood sugar level caused women to self-imposed restrictions on activities in their daily living because of possible hypoglycemia were distressing for them.

C. Following with occasional offense diabetes guideline People in this group believe that every human will be die with or without diabetes. Therefore, they try to enjoy through their life with diabetes. When they feel sick and body not comfortable, they follow the guideline, doing appropriate diet and take medication regularly because they know the effect of high blood sugar level to their body. But, when their body feel good and comfortable they break on diet and not take the medication. They think that they are not necessary to take the medication every day, because the medication will give side effect if consumed in a long time. Everyday, my spouse prepare food and medication for me. But I think everyone will die with illness or not. Through it and make it simple, so sometimes I just want to eat everything that I want, I take medication when my body feels sick, but if I feel good I do not take it. (ID17PM, 55 y.o) I have been 10 years living with diabetes, and sometimes I bored with the treatment that must take medication every day, Alhamdulillah I'm still in good condition and not have a complication. (IDO5PF, 53 y.o)

The males in this group looked very dependent on their spouse to provide their food, always remind and prepare the medication after a meal, and think that is the spouse obligation to take care of them. Javanese culture put the wife as a person that must serve the husband, take care of them, and prepare his needs. Therefore, when they are at home, they can keep their eating habit, but sometimes when they have acted outside, they tend to break on the diet. For example, when they attend the wedding party or meeting that related to their work, sometimes they cannot avoid the sweet beverages and food provided at that event. Sometimes they are difficult to reduce their portion of rice because as males they need more energy to work. As Javanese they are also difficult to avoid the rice and substitute it with other food, they called it Javanese stomach, which must eat rice every day. Sometimes they also cannot avoid their desire to eat the Javanese food that most use sugar and sweet soya sauce. The five key informants above sometimes offence diabetes guideline may cause by unawareness about their diabetes. Awareness of various aspects of diabetes is essential for the prevention, management, and control of the disease. The role of male as ahead of the family also make them eat more for energy to work. That condition makes their blood sugar levels are fluctuating. Sometimes they can keep their blood sugar at a stable level, but sometimes they have a high level that is very dangerous for their condition. This finding correlates with [19] that showed the general awareness of these aspects is low among diabetic patients in The Gambia. Study of [20]showed that Sudanese with diabetes have poorly understood and lack of awareness about diabetes. They stop their treatment when acute symptom like polydipsia and polyuria are over because they believe that diabetes can be cured.

\section{CONCLUSIONS AND RECOMMENDATION}

Based on the research finding, there are three groups of life scenery that draw the living of persons with diabetes in Javanese culture. This life scenery showed how Javanese culture, Javanese belief, value, Islam as their religion, characteristic of Javanese people, acquired information and knowledge about diabetes and its management that influenced and formed the perspective and behaviour in order to manage their daily lives with diabetes. The people in group 1 and group 2 can keep stable their blood sugar level. All of them are female that have self-awareness and discipline to follow the recommendation to manage their diabetes in their daily living. The difference between them is how they through their life with diabetes. The people in group 1 no have complication and enhance their spiritual care, therefore they feel enjoy and peaceful mind trough their daily living with diabetes. In the other hands, the people in group 2 have the worst experience that make them through their daily living with worry. People in group 3 no have complication even though 1 female diagnosed diabetes for 10 years, that make her feel boring with her treatment and sometimes offence her diet. Four of them are male and very dependent on their spouse to provide their food, always a reminder and prepare the medication after the meal, and think that is the spouse obligation to take care of them. Javanese culture put the wife as person that must serve the husband, take care of them, and prepare his needs. Therefore, when they at home they can keep their eating 
habit, but sometimes when they have acted outside the tend to break on the diet. That condition makes their blood sugar levels are fluctuating. Sometimes they can keep their blood sugar at a stable level, but sometimes they have a high level that is very dangerous for their condition. Even though they no have a complication, but if they cannot keep their blood glucose level in the stable range, they have high risk to get the complication.

The finding of this study found the new knowledge that spiritual is an important aspect of diabetes management among Javanese persons with diabetes. Javanese people who have high spiritual level showed their ability to accept their condition as a destiny from God, have the selfawareness to follow the guideline in order to manage their diabetes, enjoy their daily activity with diabetes, and performed the stable blood glucose level. The research findings from this study have several recommendations for such as 1) Nursing practice needs to understand the culture, ideas, beliefs, and practices of Javanese diabetes persons to realize the needs of care provided to them. The results of this study provide basic information about cultural management of Javanese persons living with diabetes that benefit for further study and also used to helps the HCPs to arrange and design a model of diabetes management that appropriate to Javanese culture. The health care providers need to enhance the spiritual aspect of persons with type 2 diabetes in diabetes management program; 2) Nursing education needs to involve the knowledge of Javanese culture in diabetes management into nursing curriculum and collaborate with the practice nurse and other disciplines to design and develop the guideline of diabetes that have cultural sensitivity that appropriate to Javanese people; 3) Healthcare system (BPJS) as the national health insurance in Indonesia should add the spiritual care in diabetes management guideline in order to enhance the quality of diabetes management and quality of life of Javanese persons with diabetes.

\section{REFERENCES}

[1] IDF. (2017). IDF DIABETES ATLAS Seventh Edition. https://www.idf.org/e-library/epidemiology-research/diabetesatlas/13-diabetes-atlas-seventh-edition.html

[2] United Nation. (2011). Prevention and control of noncommunicable disease: Report of the Secretary General. New York : United Nation. http://www.un.org

[3] Kementrian kesehatan RI (2013). Penyajian Pokok-Pokok Hasil Riset Kesehatan Dasar 2013. https://www.kemkes.go.id/resources/download/general/pokok2 \%20hasil\%20riskesdas\%202013.pdf

[4] Hyder, A., Morrow, R. (2005). Culture, Behavior, and Health

[5] Mertig, R.G. (2012). Nurses' Guide to Teaching Diabetes SelfManagement second edition. Springer

[6] Narayan, K.M., Williams, D., Gregg, E.W., Cowie, C.C. (2011). Diabetes Public Health. Oxford University Press.

[7] Rintala, T.M., Jaatinen, P., Paavilainen, E., Astedt-Kurki, P. (2013). Interrelation Between Adult Persons with Diabetes and Their Family: a Systematic Review of the Literature. Journal of Family Nursing 19(1) 3-28.

[8] Grzywacz, J.G., et al. (2012). Cultural basis for diabetes-related beliefs among low- and high-education African American, American Indian, and white older adults. Ethn Dis. 2012 Autumn;22(4):466-72.

[9] Lincoln and Guba. (1985). Qualitative Research Guideline Project. Sage Publication.

[10] Creswell, J.W. (2013). Qualitative Inquiry and Research Design third edition. Sage Publication
[11] Rowe M.M and Allen, R.G. (2003). Spirituality as a means of coping with chronic illness. American Journal of Health Studies, vol. 19 , pp. 62-66, 2003

[12] Cotton, S., et al. (2009). Spirituality and religion in patients with HIV/AIDS. Journal of General Internal Medicine, vol. 24, no. 8, 994 pages, 2009.

[13] Johnson et al, (2011). Which Domains of Spirituality are Associated with Anxiety and Depression in Patients with Advanced Illness?. J Gen Intern Med 26(7):751-8 https://www.ncbi.nlm.nih.gov/pmc/articles/PMC3138578/pdf/1 16062011 Article 1656.pdf

[14] Sawatzky, et al. (2005). A meta-analysis of the relationship between spirituality and quality of life. Social Indicators Research, vol. 72, no. 2, pp. 153-188, 2005

[15] Puchalski, et al. (2009). Improving the quality of spiritual care as a dimension of palliative care: the report of the consensus conference. Journal of Palliative Medicine, vol. 12, no. 10, pp. 885-904, 2009

[16] Yanez et al. (2009). Facets of Spirituality as Predictors of Adjustment to Cancer: Relative Contributions of Having Faith and Finding Meaning. J Consult Clin Psychol. 2009 August ; 77(4): 730-741. doi:10.1037/a0015820.

[17] Dunning, T. (2014). Care of People with Diabetes: A Manual of Nursing Practice. Wiley and Sons.

[18] Penckofer et al. (2007). The Psychological Impact of Living With Diabetes. Diabetes Educ. J 2007 Jul-Aug; 33(4): 680-690.

[19] Foma, M.A., et al. (2013). Awareness of diabetes mellitus among diabetic patients in the Gambia: a strong case for health education and promotion. BMC Public Health. 2013 Dec 5;13:1124.

[20] Alva, M.L. et al. (2017). Identifying risk for type 2 diabetes in different age cohorts: does one size fit all? BMJ Open Diab Res Care 2017;5:e00447. doi:10.1136/bmjdrc-2017-000447 